\title{
POR UMA PRÁXIS DE ENFERMAGEM CRIATIVA E REFLEXIVA*
}

\author{
POR UNA PRÁXIS DE ENFERM ERIA CREATIVA Y REFLEXIVA
}

\author{
TOWARDSA CREATIVE AND REFLECTIVE NURSIN G PRACTICE \\ PEDRO PAULO SCREMIN MARTINS**, MARTA LENISE DO PRADO*** \\ EKENYA SCHMIDT REIBNITZ****
}

\begin{abstract}
RESUMO
Ensaio teórico, com base nas idéias de Vazquez (1977), acerca da práxis de enfermagem - entendida enquanto práxis social específica no âmbito das práxis de saúde. Discute o significado da práxis e seus diferentes níveis, buscando compreender a práxis de Enfermagem como uma forma específica, identificando os seus elementos constitutivos. Argumenta em favor de uma práxis criativa e reflexiva de Enfermagem, reconhecendo que esta se configura numa articulação teórico-prática, fundada no conhecimento científico; práxis social específica que se constitui pela relação entre diversos atores sociais. Desta relação depende seu compromisso com a saúde do ser humano e da coletividade, com a preservação da vida; relação historicamente determinada -embora também determinante- pelo processo de produção em saúde, inserida numa relação mais ampla do respectivo modo de produção da vida em sociedade, por sua vez, principal determinante do processo de viver humano.
\end{abstract}

Descritores: Enfermagem, Filosofia em Enfermagem, Etica.

\section{RESUMEN}

El artículo es un ejercicio teórico, con base en Vázquez (1977), a cerca dela praxis de enfermería - comprendida como una praxis social específica en el ámbito de las praxis de salud. Discute el significado de la praxis y sus distintos niveles, con la finalidad de comprender la praxis deEnfermería como una forma específica, identificando sus elementos constitutivos. Argumenta a favor de una praxis creativa y reflexiva de Enfermería, reconociendo que ésta se configura en una articulación teórico-práctica, fundada en el conocimiento científico; praxis social específica que se constituye por la relación entre los diversos actores sociales. De esta relación dependesu compromiso con la salud del ser humano y de la colectividad, con la preservación de la vida; relación históricamente determinada -aunque también determinante- por el proceso de producción en salud, insertada en una relación más amplia del modo de producción de la vida en la sociedad, a su vez, principal determinante del proceso del vivir humano.

Palabras claves: Enfermería, filosofía en enfermería, ética.

\begin{abstract}
This article is a theoretical exercise concerning the practice of nursing -intended as a specific social practice within the environment of health care practices. It discusses the significance of practices on their different levels,

\footnotetext{
* Texto baseado em M ARTINS, P.P.S. Atendimento pré-hospitalar: atribuição eresponsabilidade dequem? Uma reflexão crítica a partir do serviço do corpo debombeiros edaspolíticas desaúde "para" o Brasil à luz da filosofia da práxis. Dissertação (M estrado em Enfermagem) - Centro de Ciências da Saúde, Universidade Federal de Santa Catarina, 2004.

** Enfermeiro. M estre em Enfermagem e Especialista em Enfermagem de Emergência e Terapia Intensiva. E-mail: ppsm29@hotmail.com

*** Enfermeira, Doctora em Filosofia da Enfermagem. Docente del Programa de Postgrado en Enfermería de la Universidade Federal de Santa Catarina. E-mail: mpradop@nfr.ufsc.br

**** Enfermeira, Doctora em Enfermagem. Docente del Programa de Postgrado en Enfermería de la UniversidadeFederal de Santa Catarina. E-mail: kenya@nfr.ufsc.br.
} 
looking to comprehend Nursing practice as a specific form, identifying its constructive elements. This article argues in favor of a creativeand reflective nursing practice, recognizing that such a practice is constructed within a theoretical-practical articulation, founded upon scientific knowledge; a specific social practice that is constituted by the relationship between diverse social actors. Our commitment to human and collective health and the preservation of life depends upon this relationship. It is a relationship historically determined -though also determining- through the process of production in health, inserted into a more ample relationship from the respective mode of society's life production, which, on its own is a principal determinant of the process of human living.

Keywords: Nursing, Philosophy nursing, Ethics.

Fecha de recepción: 06/12/05. Fecha aceptación: 18/10/06.

\section{ENFERMAGEM: UMA FORMA ESPECÍFICA DE PRÁXIS?}

Pensar a Enfermagem como práxiséum exercício instigantequenosfaz refletir sobreo seu sentido e como se pode ascender a níveis em que predominem a criatividade e a reflexão; contribui para a compreensão, numa outra perspectiva, da relação entre teoria e prática. Neste artigo, faremosesta reflexão a partir das idéias de Vazquez (1977), expressas em sua Filosofia da Práxis.

No interior da práxis social, como na histórica, seinter-relacionam diversasformas de práxis, dentre as quais "o trabalho, a arte, a política, a medicina, a educação, etc." (Vázquez, 1977). A partir desteentendimento, acrescentamos a Enfermagem enquanto práxis social específica. Ou seja, a Enfermagem é uma das formas depráxis situada no âmbito das práxis de saúde, as quais compõem um conjunto de ações no processo saúde-doença, voltadas a satisfazer determinadas necessidades humanas. “... as formas específicas de práxis, nada mais são do que formas concretas, particulares, deuma práxis total humana, graçasà qual o homem como ser social e consciente humaniza os objetose se humaniza a si próprio" (Vázquez, 1977).

Ao aprofundar os estudos sobre a filosofia da práxis, foi possível realizar algumas abstrações que provocaram a elaboração deidéias para a compreensão da práxis de Enfermagem, como práxis social específica. Uma práxis que tem sua origem no cuidado ao ser humano (Silva, 1989); mas que, em decorrência do modo de produção e do elevado nível de desenvolvimento tecnológico e científico da sociedade contemporânea, tal centralidade de atuação no cuidado direto ao ser humano, passa a ser permeada por uma diversidade de formas de organização das atividades e do processo prático em saúde. Em virtude destas mudanças e/ou transformações sociais ocorridas ao longo da história da humanidade, foram sendo incorporadas outras características, entendidas por Silva (1989), como cuidado indireto. Em virtude disso, se considerarmosquetoda forma de práxis social tem em comum o ser humano como matéria ou objeto sobreo qual age o sujeito - quer se trate da sociedade, quer se trate de indivíduos concretos- equea Enfermagem éuma forma específica de práxis social, cabe-nos questionar: o que há de específico na práxis de Enfermagem que a torna uma expressão particular da práxis social total? Q ual a importância de se conhecer as especificidades desta práxis?

Fazendo uma analogia da práxis deEnfermagem com as principaisformas de práxis em torno das quais o autor ( Vázquez, 1977) discorre sua obra, podemos dizer que, diferentemente da práxis produtiva que é uma relação do homem (sujeito) com a natureza (objeto), na práxis de Enfermagem -enquanto práxis social específica- o ser humano é sujeito e objeto da ação. Por sua vez, se o ser 
humano define-se essencialmente como ser prático e, através da práxis, produz, forma ou transforma a si mesmo, sem dúvida, tal processo ocorre com certasingularidadena práxis social e por conseguinte na práxis de Enfermagem, tendo em vista que, ambos, sujeito e objeto da práxis são dotados de consciência, vontade esensibilidadee aspiram realizar suas intenções, perseguindo seus próprios objetivos no âmbito de uma sociedade que é um complexo de práxisespecíficas, uma totalidade prático-social, permeada de contradições. Se o ser humano na práxis social é sujeito e objeto, significa dizer que, na condição de objeto pode envolver-se conscientemente no exercício da práxis - mesmo sem dominar os instrumentos da práxis-, bem como, na condição de sujeito, ter a intenção de transformar uma certa realidade, tornando-a mais humana. Para Ribeiro (2001):

... admitir a condição [humana] não só de agente, mas também de matéria-prima e de instrumento, não equivalea admitir queo ser humano seja tomado como qualquer outra matéria inerte e que assim possa ser submetido ao sabor dos caprichos e das necessidades apenas dos outros seres humanos.

Em suma, na condição deobjeto da práxis deEnfermagem - assim como em toda práxis social-, o ser humano pode, de um lado, aderir conscientemente ao projeto prático transformador etornar-se real mente objeto-sujeito da respectiva práxis, ou, de outro lado, negar esta práxis tornando-se efetivamente sujeito de uma antipráxis que, ao contrário da práxis, tem objetivos que aspiram a conservação ou a manutenção de um determinado estado de coisas desumanizadas e desumanizantes. Por isso, apontamos para uma práxis de Enfermagem concretizada numa relação entresujeitos, queadiram a um projeto transformador, considerando que, na posição de objeto da práxis o ser humano também é sujeito, ou seja, éativo.

\section{Elementos constitutivos da práxis em geral}

Para conhecer a particularidade deuma práxis específica é preciso delimitar os elementos constitutivos da práxis em geral, assim como, desvelar seus sentidos.

Os elementos constitutivos, como particularidade da práxis específica, por um lado, só adquirem sentido em sua relação com a totalidade, por outro, só realizam estesentido para esta mesmatotalidade dando conta do quelhe é particular, do que Ihe é específico. Em outras palavras, numa práxis específica - seus sujeitos- precisam conhecer e exercer o que Iheéespecífico para realizar o sentido da respectiva prática e contribuir com a totalidade da práxistransformadora. Assim, o verdadeiro sentido só pode ser buscado na relação entre o particular -forma específica- e o geral - práxis total humana- (Ribeiro, 2001).

Para compreender este sentido particular de uma forma específica de práxis, é preciso um exercício de abstração da realidade, ou melhor, da práxis social total e, ao fazêlo é possível distinguir que a totalidade constituise de vários elementos que envolvem e estão envolvidos pela atividade humana, dentreestes: sujeito, objeto, instrumentos, finalidades e produto da práxis, voltados à realização de um significado comum a todas formas de práxis.

O sujeito da práxis, ou agente, éum ser prático (teórico-prático), dotado de consciência, sensibilidade, vontade de criar e produzir para satisfazer suas necessidades humanas, "do estômago à fantasia" (M arx, 1996). Este ser, é, em razão, o ser humano; esua"atividadepropriamente humana só se verifica quando os atos dirigidos a um objeto para transformálo se iniciam com um resultado ideal, ou finalidade, e terminam com um resultado ou produto efetivo, real" (Vázquez, 1977). Portanto, a práxis, como atividade propriamente humana, diferentemente das atividades bio- 
lógicas ou instintivas - da qual o homem também pode ser sujeito - que não transcendam de seu nível meramente natural, é determinante (Vázquez, 1977). Sua atividade propriamentehumana é dotada deum caráter consciente, intencional, haja vista que, as finalidades são determinadas por necessidadeshumanas que precisam ser satisfeitas (Ribeiro, 2001). A práxis então, se distingue radicalmente de qualquer outra atividade situada num nível meramentenatural, porqueimplica na interven ção da consciência, através da qual o produto existe duas vezes - e em tempo diferentes: como resultado ideal ecomo produto real.

A finalidade da práxis se caracteriza em "virtude dessa antecipação do resultado que sedeseja obter..." (Vázquez, 1977). Como afirma, Martins (2004),

a atividade humana é, por conseguinte a atividade que se desenvolve de acordo com finalidades, e essas só existem através do homem, como produtos de sua consciência. Toda ação verdadeiramente humana requer certa consciência de uma finalidade que se sujeita ao curso da própria atividade. A finalidade, por sua vez, éexpressão de certa atividade do sujeito em face da realidade.

A rigor, o sujeito da práxis, dirige seus atos a determinados objetos para transformá-los de acordo com finalidades - atos que se iniciam com a antecipação, consciente e ideal do resultado real.

Cada forma específica de práxis tem seu objeto particular. Tais objetos, ou matéria-prima sobreo qual o ser humano exercesua ação, pode ter natureza diversa: corpo físico, ser vivo, vivência psíquica, grupo, relação ou instituição social (Vázquez, 1977). Na práxis específica, a natureza da matéria sobre a qual o ser humano exerce a ação para operar uma transformação, deve ser especificada, determinada, conhecida em sua essência. 0 produto da práxis é o resultado real, adequado intencionalmente pelo ideal, por sua vez subordinado àsintempéries no decorrer do pro- cesso prático; éa matéria-prima transformada, levando-se em conta que a finalidade original (ideal) sofre modificações, às vezes radicais, no decorrer do processo prático.

Um outro elemento ainda convém ser destacado - tal sua importância- que é, os instrumentos da práxis. Estes podem ser "os recursos, construídos ou não pelos própriosseres humanos, dos quais lançam mão para, transformando a matéria prima verem transformadas em produtos as finalidades que dirigiram esta atividade transformadora" (Ribeiro, 2001). Porém, pode ocorrer uma diversidade na natureza dos instrumentos como ocorre na matéria-prima eno produto, enão obstante, deles dependem, também, a adequação da práxis à finalidades.

Embora a apresentação destes elementos pareça linear, a práxis, por ser atividade humana adequada a finalidades, é movimento constante, e seus elementos constitutivos se apresentam, realmente, num movimento dinâmico de relativa dependência e autonomia entresi. Nesta dinâmica que constitui a práxis, enquanto atividade humana consciente,

(...) algo que em uma circunstância aparece como matéria-prima ou produto, em outra pode aparecer como instrumento e vice-versa; algo que em determinada circunstância aparece como produto, em outra pode aparecer como matéria-prima; algo que aparece como agente (ser-humano), em outra pode aparecer, a um só tempo, como agente, instrumento e/o matéria prima (Ribeiro, 2001).

Em face disso, se consideramos que o homem " [...] ao atuar [...] sobre a Natureza externa a ele e ao modificá-la, ele modifica, ao mesmo tempo, sua própia natureza (Marx, 1996), devemos salientar um aspecto fundamental da dinâmica dos elementos constitutivos da práxis: "o ser humano ésemprea um só tempo, agente e produto de sua ação, portanto, da atividade propriamente humana" (Ribeiro, 2001). A premissaévalida para toda práxis específica, e por isso o sujeito de uma determinada prática, ao agir sobreseu objeto 
- utilizando-se de conhecimentos específicos (instrumentos) por ele produzido ou adaptado (traduzidos)- com a finalidade desuprir determinadas necessidades humanas, sofre reflexos na sua individualidade e sociabilidade, na sua forma de pensar e de agir, quetambém são específicos.

\section{Elementos constitutivos da práxis de enfermagem}

Precisamos então, fazer uma "tradução" dos elementos constitutivos apresentados sobrea práxis em geral para a práxis deEnfermagem, delimitando suas especificidadesa fim dedesvelar quais dos elementos a tornam uma expressão particular da práxis em geral.

O primeiro indício dequea totalidadeprático-social -que inclui todas as formas de práxis- e, por sua vez, a práxis social se decompõe em formas específicas de práxis, refere-se ao objeto sobre o qual o sujeito age para transformá-lo, que “... pode mudar, dando lugar a diversas formas de práxis" (Vázquez, 1977). Entretanto, é possível também, que o objeto da práxis seja o mesmo para diferentes formas de práxis. Por exemplo, é possível considerar a madeira como sendo matériaprima tanto da "práxis produtiva", isto é, da "relação material etransformadora queo homem estabelece-mediante seu trabalho- com a natureza" eda "práxisartística", isto é, "a produção ou criação de obras de arte" (Vázquez, 1977). Ou seja, a madeira ora aparece como objeto da práxis do operário de uma indústria de móveis, ora como objeto sobre o qual age 0 artista para esculpir sua obra. Logo, a matéria-prima ou objeto, não ésuficientepara determinar a especificidade de uma práxis.

Os instrumentos, de um modo geral, também não são suficientes. Por exemplo, na práxis desaúde, um estetoscópio podeser instrumento da práxis tanto do enfermeiro, quanto do médico e por isso, não as define. Todavia, com o advento da sociedade moderna (capitalista), através da qual se consolida a ciência, a prática de cuidados, transforma-se - sem, contudo, deixar de coexistir- em profissão, institucionalizada. M edianteesta transformação, convém destacar queaciência passa a exercer forte influência na prática de cuidados e, em se tratando de prática de Enfermagem profissional, ela não se utiliza de qualquer conhecimento como instrumento, mas sim do conhecimento científico. Os sujeitos desta práxis passam a agir e desenvolver-se com base no conhecimento científico, distanciando-se do cuidado comum que permane ce inerente ao ser humano em sua vivência em grupos sociais, especialmente o familiar. A prática de Enfermagem, então, passa a caracterizar-se pela construção de um corpo de conhecimento próprio, traduzido das ciências naturais e sociais - 0 qual seus agentes têm de necessariamenteapreender para poder agir dentro de um padrão determinado por normas legais e morais. Diante desta realidade, podemos dizer que, dentre os instrumentos, existeum quetem seconvertido num elemento essencial nesta distinção: o conhecimento científico. Este, sem dúvidas é um dos principais instrumentos que o sujeito da práxis usa para adequar suas finalidades e, portanto, 0 elemento constitutivo fundamental que possibilita galgar o mais elevado nível de práxis.

0 conhecimento científico tem particularidades que remetem, ou são úteis, a determinadas práticas. Ou seja, o conhecimento científico sobreo uso do estetoscópio éo instrumento através do qual o sujeito direciona sua atividade que é atender uma determinada necessidade humana. Enquanto instrumento da práxis, apesar de ter particularidades ou especificidades que se voltam a determinadas práxis, por si só, também não define a práxis se, seu uso não estiver adequado a finalidades específicas.

A questão que se coloca então, é: qual dos elementos constitutivos da práxis se altera nas diferentes práticas- e, ao alterar-se, de termina uma forma específica de práxis? Se gundo o Vázquez (1977), o que altera é a natureza da necessidade humana a qual deter- 
mina a atividade do ser humano sobre 0 objeto. O u seja, se "o objeto da atividade prática é a natureza, a sociedade ou os homens reais, a finalidade desta atividade é a transformação real, objetiva, do mundo natural ou social para satisfazer determinada necessidadehumana" (Vázquez, 1977) (grifo nosso). Em outros termos, o que determina a práxis específica é a natureza da necessidade humana que ela satisfaz. Por exemplo, o uso do estetoscópio, bem como, o conhecimento científico que o reveste, é específico da práxis de Enfermagem quando a sua finalidade é o de prover cuidado de Enfermagem. Da mesma forma remete-se à práxis médica, quando a finalidadeéatender uma necessidade de cura/ tratamento de uma doençal. A natureza da necessidade humana

determina a finalidade imediata ( particular) através da qual se realiza concretamenteo significado mais geral e fundamental da práxis para o ser humano, pela mediação da realização do significado específico. A mudança da necessidade determina, desse modo, a mudança da natureza da finalidade imediata (Ribeiro, 2001) (grifo da autora).

Assim, o objeto, a necessidade humana e, conseqüentemente a finalidade, acabam por impor mudanças nos instrumentos (Ribeiro, 2001), que se tornam cada vez mais específi$\cos$.

Não obstante, certas ressalvas cabem ao conhecimento científico. Este se torna um instrumento específico quando a finalidade imediata da práxis está determinada; quando está voltado a operar sobre determinada necessidade humana. Conseqüentemente, o conhecimento científico, enquanto instrumento essencial da práxis, deve ser tão específico quanto a respectiva práxis específica quefundamenta, tendo em vista que, a natureza da

\footnotetext{
${ }^{1}$ Mesmo com especificidades adequadas à finalidades, não deixa de ter pontos em comum, haja vista que, neste exemplo, é sempre instrumento da práxis mais geral: atender uma necessidade de saúde.
}

necessidade humana a ser suprida, também é específica.

Vimos que, na esfera das práxis sociais, 0 objeto das práxis sociais específicas é sempre o ser humano (individual ou social) em todas as suas dimensões e que, por outro lado, 0 instrumento do conhecimento científico, modifica-se consideravel mente, tomando diferentes formas ou adaptações, deacordo com a necessidade humana que determina a finalidade e, por conseguinte a especificidade da práxis. Quando se trata da práxis de Enfermagem profissional, aquela pela qual seus agentes passam por um preparo formal, fundado no conhecimento científico -e por isso supera a Enfermagem tradicional, leiga- a necessidade humana a ser suprida pode ser definida como cuidado deEnfermagem. Como toda práxis éhistoricamente determinada, na sociedade contemporânea 0 atendimento da necessidade humana de cuidado, pela Enfermagem -de acordo com o estágio atual do conhecimento científico-, pode sedar deforma direta (cuidado direto) ou indiretamente (cuidado indireto) (Silva, 1989). Em vista disso, a finalidade imediata da práxis de Enfermagem é determinada diretamente pela satisfação das necessidades humanas de cuidado. Seu objeto, o homem, não se caracteriza apenas como um corpo biológico, mas sim, como um corpo dotado de consciência e inserido numa trama de relações sociais; em suma, é síntese dos processos biológicos, psíquicos, sociais e históricos. M esmo conformando certa unicidade/ individualidade, cada qual contém na sua essência a característica de ser humano, o que faz com que o homem carregue consigo a eterna necessidade de cuidado - no processo de viver saudável, de adoecer edemorrer-, que por suavez requer uma prática para satisfazê-la. Nesses termos, a práxis de Enfermagem está imediatamente determinada pela finalidade de satisfação da necessidadehumana decuidado - quetodo ser humano tem, desdeos primórdios da sua existência- que, por sua vez, 
[...] significa a garantia direta da continuidadeda vida do grupo, da espéciehomo. [...] Os homens [...] sempre precisaram decuidados, porquecuidar, tomar conta, éum ato devida quetem primeiro, eantes detudo, como fim, permitir à vida continuar, desenvolver-se, e assim lutar contra a morte: morte do indivíduo, morte do grupo, morte da espécie (Backes, 2000).

Logo, a prática de cuidados é inerente ao ser humano, pois, o acompanha desde o momento em que se fez homem. Uma prática que, como qualquer outra, exigeconhecimento, pois este é o instrumento fundamental de toda forma de práxis; da ação dos sujeitos sobre determinado objeto para transformá-lo.

(...) a prática como atividadeobjetiva etransformadora da realidade natural e social (...) implica um certo grau de conhecimento da realidade que transforma e das necessidades que satisfaz (Vázquez, 1977).

A práxis de Enfermagem, por sua vez, requer conhecimento científico.

Convém salientar apenas que, mesmo tendo este entendimento da finalidade imediata à qual a prática de Enfermagem se subordina e que lhe confere significado específico, particular, não épossível ignorar ou, ainda queseja, esquecer que esta atividade humana, como todas outras, é determinada pela finalidade mais geral, universal e, portanto, de caráter mediato de satisfação da necessi dade de todo ser humano de se produzir ser humano (Ribeiro, 2001).

\section{RUMO À PRÁXIS CRIATIVA E REFLEXIVA DE ENFERMAGEM}

Diante do exposto, podemos concluir que a Enfermagem, de um modo geral, configurase numa articulação teórico- prática efundada no conhecimento científico; uma práxis social específica que se constitui pela relação entre diversos atores sociais envolvidos no processo prático. É desta relação social que depende seu compromisso com a saúde do ser humano e da coletividade, em suma, com a preservação da vida; relação esta, historicamente determinada - embora também determinante- pelo processo de produção em saúde inserida numa relação mais ampla do respectivo modo de produção da vida em sociedade, por sua vez, principal determinante do processo saúde-doença.

O desenvolvimento da práxis de Enfermagem -institucionalizada- na sociedade moderna passou por diferentes estágios ou períodos, atingindo diferentes níveis de práxis (Backes, 2000). Por conseguinte, a importânciadeseconhecer as particularidades das práxis específicas reside no fato de que, é condição fundamental para concretizar as possibilidades-objetivas e subjetiva- de transitar níveis el evados de criação, reflexão e efetivamente atingir uma autêntica consciência da práxis. Em outros termos, toda e qualquer forma específica de práxis, precisa deum lado relacionar-se com a totalidade prático-social e por outro conhecer e exercer o que lhe é específico, particular; condição sem a qual não épossível elevar-se ao mais alto grau de criação e reflexão e contribuir, no seio da práxis total, com a humanização do ser humano, adquirindo e realizando, deste modo, seu sentido e significado de práxis específica.

Os instrumentos permitiram ao homem alterar a natureza, a si mesmo e a se tornar homem, passando por diferentes estágios e alcançando distintos níveis de práxis; os instrumentos são a 'extensão da mão': instrumento original do homem (Vázquez, 1977) que, por seu vínculo com a consciência permite o homem criar outros instrumentos. Dentre estes, possivelmente, o conhecimento científico seja o mais importante, dinâmico e em constante evolução. Entretanto, tal como a mão, queservedeum lado, por exemplo, para acariciar/aproximar os homens e, de outro, para brigar, o conhecimento científico também pode ter finalidades opostas a depender 
do uso que se faça dele. Por isso, o ser humano precisa ter domínio sobre os instrumentos da práxis para usá-los de acordo com suas finalidadesque, essencialmente, visam à transformação para humanização do mundo natural e social.

Sendo assim, concluímos pela necessidade da práxis deEnfermagem - como todas as outras- priorizar o domínio do conhecimento científico, importante instrumento da práxis. M as não somente isto. Precisamos ter consciência da práxis de Enfermagem para que o conhecimento científico, quando específico desta práxis, seja adequado à sua finalidade imediata, ou seja, de satisfazer necessidadeshumanas decuidado. E, paraisso, épreciso a formação de profissionais que saibam pensar, capazes de cultivar o pensamento complexo, para o qual a contribuição da filosofia éfundamental (Reibnitz \& Prado, 2003).

A consciência da finalidade da práxis de Enfermagem, em adição ao domínio do conhecimento científico, é condição fundamental para o exercício de uma práxis criativa e reflexiva. Certamente, já atingimos um estágio de desenvolvimento no qual estão maduras as premissas teóricas necessárias para que possamos assumir a consciência filosófica da práxis de Enfermagem e elevá-la. Elevar a consciência filosófica da práxis significa que os homens precisam esclarecer teoricamente sua prática social, para regular conscientemente suas ações como sujeitos da história (Vasquez, 1977). E para que essas ações se revistam deum caráter criador, énecessário também hoje, mais do que nunca, uma elevada consciência das possibilidades objetivase subjetivas do homem como ser prático, ou seja, uma autêntica consciência da práxis. Considerando que a saúde é condição sem à qual o ser humano não pode suprir sua necessi dade humana de transformar criativamenteo mun- do natural e social para fazer dele um mundo maishumano econseqüentementereproduzirse como ser humano, o produto da prática de Enfermagem não pode ter outro caráter que não seja o universal e igualitário. A práxis de Enfermagem tem como finalidade, antes de tudo, garantir um atendimento com qualidade à saúde de pessoas; suprir necessidades humanas de cuidado (M artins, 2004). Gal gar níveis em que predominem os níveis da criação e reflexão, significa atender com maior qualidade tais necessidades, al cançando uma práxis com maior grau de transformação do seu objeto, tendo no horizonte a humanização do ser humano. Esta práxis, elevada ao mais alto grau deconsciência filosófica, onde se encontra o nível criador e reflexivo, é condição necessária para fazer deste mundo um mundo mais humano.

\section{REFERÊNCIAS}

Backes, V.M .S. (2000). Estilos depensamento epráxis na enfermagem: a contribuição do estágio préprofissional. Ijuí (RS): UNIJUÍ.

Martins, P. P. S. (2004). Atendimento pré-hospitalar: atribuição eresponsabilidade dequem? Uma reflexão crítica a partir do serviço do corpo de bombeiros e das políticas de saúde "para" o Brasil à luz da filosofia da práxis. Dissertação de M estrado em Enfermagem não publicada, Programa dePós-Graduação em Enfermagem, Universidade Federal de Santa Catarina.

M arx, K . (1996) . O capital: Crítica da economia política. São Paulo: N ova Cultural.

Reibnitz, K.S., Prado, M. L. (2003). Formação do profissional crítico-criativo: a investigação como atitude de (re)conhecimento do mundo. Rev. Texto Contexto Enferm., 12, 26-33.

Ribeiro, M.L. S. (2001). Educação escolar: que prática é essa. Campinas (SP): Autores Associados.

Silva, G.B.S. (1989). Enfermagem profissional: Análise crítica. São Paulo: Cortez.

Vázquez, A.S. (1977). Filosofia da práxis. Rio de Janeiro: Paz e Terra. 